\title{
Have the same pathogenicity of Ureaplasma Parvum and Ureaplasma Urealyticum in non- specific cervicitis? -based on digital droplet PCR assay
}

\author{
Yanfang Huang \\ Minhang Hospital, Fudan University \\ Xiaoqin Xu \\ Minhang Hospital, Fudan University \\ Panpan Lv \\ Minhang Hospital, Fudan University \\ Zhen Zhao ( $D$ zhaozhen_863@126.com ) \\ Minhang Hospital, Fudan University
}

\section{Research Article}

Keywords: Ureaplasma parvum, Ureaplasma urealyticum, qPCR, droplet digital PCR, 31 Absolute Quantitation, cervicitis

Posted Date: March 29th, 2021

DOI: https://doi.org/10.21203/rs.3.rs-284649/v1

License: (c) (1) This work is licensed under a Creative Commons Attribution 4.0 International License. Read Full License

Version of Record: A version of this preprint was published at BMC Infectious Diseases on August 11th, 2021. See the published version at https://doi.org/10.1186/s12879-021-06355-6. 
Have the same pathogenicity of Ureaplasma Parvum and Ureaplasma Urealyticum in non-specific cervicitis? -based on digital droplet PCR assay. Yanfang Huang ${ }^{1}$, Xiaoqin $\mathrm{Xu}^{1}$, Panpan $\mathrm{Lv}^{1}$, Zhen $\mathrm{Zhao}^{1 *}$ Clinical Laboratory, Minhang Hospital, Fudan University, Shanghai, China. *The corresponding author: Zhen Zhao. Address: No. 170, Xinsong Road, Shanghai, China. Telephone: +8613916269968 . E-mail address: zhaozhen_863@126.com.

1 Abstract:

Background: Ureaplasma spp. are association with a various of infectious diseases in female, but it still limited evidence for the pathogenicity in nonspecific cervicitis. The aim of this study was to develop and evaluate a digital droplet PCR (ddPCR) assay for quantified the load of Ureaplasma spp in cervical swabs.

Methods: A total of 293 non-specific cervicitis (NSC) patients and 211 asymptomatic female fulfilled the inclusion criteria. Cervical swabs were identified by qPCR and further absolutely quantified by ddPCR.

Results: The prevalence of U.parvum were 51.9\% (152/293) and 46.9\% (99/211); while U.urealyticum were $8.2 \%(24 / 293)$ and $8.1 \%(17 / 211)$ in the NSC and Control group, respectively. In addition, the average $\mathrm{Ct}$ value and median copy number of U.parvum were $31.33(\mathrm{n}=152)$ and $5.99 \times 10^{5}$ copies/ml $(\mathrm{n}=48)$ in the NSC group and $33.68(\mathrm{n}=99)$ and 1.74 
$10^{4}$ copies $/ \mathrm{ml}(\mathrm{n}=33)$ in control group, respectively, suggest that the load of U.parvum of NSC group were significantly higher than the asymptomatic individual $(P<0.001)$. But, the median load number of U.urealyticum were $1.26 \times 10^{3}$ copies $/ \mathrm{ml}(\mathrm{n}=22)$ and $5.35 \times 10^{3}(\mathrm{n}=14)$ copies per microliter two groups, the difference was no statistical significance $(P>0.05)$.

Conclusions: our study suggests that often carrying U.parvum at a high load but not

U.urealyticum may have an important implications on the development and progression of cervicitis among female.

Keywords: Ureaplasma parvum, Ureaplasma urealyticum, qPCR, droplet digital PCR, Absolute Quantitation, cervicitis

\section{Introduction:}

Ureaplasma spp. has 14 known serotypes and subdivided into two biovars: Ureaplasma urealyticum (U.urealyticum) and Ureaplasma parvum (U.parvum). This pathogen is suspected to be the causative agents of non-gonococcal urethritis[1], bacterial vaginosis[2], cervicitis[3], and multiple adverse pregnancy outcomes that include spontaneous preterm birth[4], chorioamnionitis[5], preterm premature rupture of membranes (PPROM)[6]. Currently, the role of Ureaplasma spp. remains controversial[7, 8], largely due to high rates of isolation of

41 these bacteria from the urogenital tract of a seemingly asymptomatic adult. Many pathogens such as HPV, C. trachomatis, and $N$. gonorrhoeae have been confirmed to be causative factors of cervicitis, but more work is required to gain a clear understanding of the cervicitis associated with Ureaplasma spp. 
The European STI Guidelines Editorial Board states stated that there is insufficient

47 evidence that Ureaplasma spp. can cause cervicitis and not recommended the routine testing of asymptomatic or symptomatic females for the presence of Ureaplasma spp. [9], of note, except in cases of high bacterial load[10, 11]. However, the quantified bacterial load at all previous studies have taken the qPCR technology that referred to external references. Several studies showed that ddPCR had much higher sensitivity and is more than resistant to PCR inhibition than qPCR $[12,13]$. Moreover, a recent study suggested that the copy numbers obtained by qPCR were higher between 1 and 31 times compared to ddPCR (mean: 9.7; SD

7.7)[14]. Regarding digital droplet PCR (ddPCR), is a method of absolute nucleic acid quantification without external references and robustness to variations in PCR efficiency[15, 16].

Hence, after the screening the positive of Ureaplasma spp specimens by qPCR, we take a more precise ddPCR technology to accurate quantification of Ureaplasma spp. in partly suspicious positive cervical swabs. In this study, we investigated the prevalence and aimed to unequivocal quantified a load of Ureaplasma spp. in non-specific cervicitis patients and inquire into the pathogenicity of two Ureaplasma biovars.

\section{Study population}


From July 2019 to November 2020, patients attending the gynecology outpatient or health clinic in Minhang Hospital, Fudan University were recruited. All of the women were aged $\geq 18$ years, has exhibited symptoms of cervical discharge (purulent or mucopurulent endocervical exudate) or cervical bleeding[17], had not been received the gynecologic intervention and antibiotics treatment in the preceding 3 months, had not used intrauterine contraceptive device, had been sexually activated in last 3 months and were not currently pregnant or menstruating. 11.3), and 211 asymptomatic females were the control group (mean age $43.7 \pm$ SD 8.4).

\section{Specimen collection and DNA extracting}

Cervical swab samples were obtained according to protocols performed by experienced clinicians. T. vaginalis and Fungal were examined under a microscope. Total DNA from 200 $\mu l$ fresh cervical swabs were extracted from the supernatant using MiniBest Universal Genomic DNA Extraction Kit (Takara) following the manufacturer's instruction. Extracts were resuspended in $100 \mu \mathrm{l}$ of Nuclease-Free Water. DNA samples were stored at $-20^{\circ} \mathrm{C}$ or $-80^{\circ} \mathrm{C}$ until use. The concentration of nucleic acids was determined with a NanoDrop 2000 Spectrophotometer (Thermo Scientific, USA). Human papillomavirus (HPV), C.trachomatis, or N.gonorrhoeae were confirmed by the commercial kits based on the TaqMan probes (Kehua, Shanghai, China) according to the manufacturer's instructions. U.parvum serovar 1 (ATCC 27813) and U.urealyticum serovar 4 (ATCC 27816) were used as standard strains. 
The nucleotide sequence of 14 servers of Ureaplasma spp. was download from the

GenBank and aligned using Mega X software [18]. The primers and TaqMan probes were designed by Primer Express 3.0 (Applied Biosystems, Foster City, CA, USA) based on the parC gene conserved regions of U.parvum and U.urealyticum, respectively (Table no.2 and Appendix 1). The TaqMan probes of target genes and house-keeping genes were marked with FAM and VIC at 5' terminal, respectively (Table no. 1). The same primers and probes were used in both qPCR and ddPCR reactions.

95 
111 Mastermix for ddPCR included $1 \times$ ddPCR Supermix for Probes (no dUTP), 20X target/

112 reference primers/probes mix (including the $900 \mathrm{nM}$ target and reference primers as well as $250 \mathrm{nM}$ target probe (FAM-labelled) and reference probe (VIC-labelled)) together with $9 \mu \mathrm{l}$ sample DNA. The generation of droplets was performed by the QX200 Droplet Generator according to the manufacturer's protocols. PCR amplification was carried out on an Applied Biosystems Veriti 96-Well Thermal Cycler using the following PCR conditions: $95^{\circ} \mathrm{C}$ for 10 min followed by 40 cycles of denaturation at $94^{\circ} \mathrm{C}$ for $30 \mathrm{~s}, 60^{\circ} \mathrm{C}$ for $1 \mathrm{~min}$ and the enzyme was deactivated at $98^{\circ} \mathrm{C}$ for $10 \mathrm{~min}$. The plate was stored at $4^{\circ} \mathrm{C}$ until droplets were analyzed by the QX200 Droplet Reader and QuantaSoft software version 1.7.4 (Bio-Rad). In each run a non-template control were included. Threshold between positive and negative droplet populations were set manually using per-plate positive and no-template controls as a guide. Usually, droplets with an amplitude above 6,000 were considered positive for the U.parvum assay, above 2,000 were considered positive for the U.urealyticum assay. Standardized copies mean that copy number of U.parvum or U.urealyticum divided by copy number of GAPDH gene and multiply by a thousand.

\section{Statistics} in Stata 13.0 (StataCorp, TX, USA) and visualized using GraphPad Prism 8 Software, Inc (La Jolla, CA, USA). T-test were used to compare the differences between the two groups. 


\section{Results}

Firstly, we confirmed the diagnosis performance of primers and probe by qPCR. As

Supplement Figure no. 1 shown, the primers of U.parvum and U.urealyticum identified the great specificity by melt curve. Besides, the primers targeted U.parvum can amplify the four serotypes (Up1, Up3, Up6, Up14) from national standard strains, similarly, the primers targeted U.urealyticum can amplify the ten serotypes (Uu2, Uu4-5, Uu7-13).

After the clinical test for HPV infection by experienced medical staff, the HPV-negative cervical swab was further examined under a microscope to rule out fungal and trichomonas infection. 538 specimens performed the C.trachomatis, N.gonorrheae, U.parvum, and U.urealyticum test by qPCR in quadruplicate. Finally, a total of 504 samples enrolled in this study, including 211 asymptomatic persons and 293 non-specific cervicitis patients (table no. no. 1).

According to qPCR, The prevalence of U.parvum was $51.9 \%(152 / 293)$ and $46.9 \%$ (99/211); U.urealyticum was 8.2\% (24/293) and 8.1\% (17/211) ); mixed infection was 3.8\% $(11 / 293)$ and $2.4 \%(5 / 211)$ in NSC and control group, respectively (Table no. 3). There was no significant difference between any two groups $(P>0.05)$. Moreover, the mean $\mathrm{Ct}$ of U.urealyticum was $33.16(\mathrm{n}=24)$ and $34.97(\mathrm{n}=17)$ in two groups, there is also not statistics significantly $(P=0.196)$ (Figure no.2 and Table no.3). However, the mean Ct of U.parvum in the NSC group was Ct is $31.33(\mathrm{n}=152)$, compared with the mean of Ct value of U.parvum in 
the control group is $33.68(\mathrm{n}=99)$, there is a significant difference in two groups $(P<0.0001)$ (Figure no. 2 and Table no. 3).

The diagnostic performances of ddPCR were excellent (Supplement Figure no.3). A total of 95 U.parvum positive specimens according to the digital random method (Mean Ct valuve: $31.89 \pm 4.03$ ) and all 40 U.urealyticum positives specimens (Mean ct valuve: $34.01 \pm 4.46$ ) performed the ddPCR. Of note, a total of 14 specimens with the average Ct of U.parvum was $37.24 \pm 1.73$ were not detected of $U$.parvum by ddPCR. Similarly, the copies of 3 cases out of 40 positive specimens for U.urealyticum were zero copy by ddPCR, in which the average $\mathrm{Ct}$ was $38.00 \pm 0.35$ (data not shown). Moreover, both methods showed a high degree of linearity (U.parvum-qPCR: $\mathrm{R}^{2}=0.998$ and U.parvum-ddPCR: $\mathrm{R}^{2}=0.998$, supplement Figure no.2; U.urealyticum-qPCR: $\mathrm{R}^{2}=1$ and U.urealyticum-ddPCR: $\mathrm{R}^{2}=1$, Figure no.1) but ddPCR has a smaller dynamic range and higher precision in the low copy sample (Figure no. 1). As Figure no. 3 showed, there was a strong correlation between the absolute copy number of ddPCR and Ct value of $\mathrm{qPCR}$ about U.parvum $\left(\mathrm{n}=81, \mathrm{R}^{2}=0.80\right)$, while the correlation with U.urealyticum was relatively poor $\left(n=37, R^{2}=0.50\right)$.

In ddPCR, the median bacteria load for U.parvum was $5.99 \times 10^{5}$ copies $/ \mathrm{ml}$ in the NSC group $(\mathrm{n}=48)$ and $1.74 \times 10^{4}$ copies/ml in the control group $(\mathrm{n}=33)$, respectively. However, the median load for U.urealyticum was $1.26 \times 10^{3}$ copies/ml in the NSC group $(n=22)$ and $5.35 \times 10^{3}$ copies $/ \mathrm{ml}$ in the control group $(\mathrm{n}=14)$, respectively (Table no. 4). U.parvum has significant differences between the NSC group and the control group in terms of Ct value of qPCR, copy number, and standardized copy number (copy number of U.parvum divided by 
copy number of GAPDH gene) by ddPCR $(P<0.0001)$. On the contrary, U.urealyticum has no significant differences no matter one of three aspects in two groups $(\mathrm{P}>0.05)$ (Figure no. 3).

\section{Discussion}

So far, there is only limited convincing evidence that U.parvum and U.urealyticum are the causative agents of non-specific cervicitis infections, partly because of lack of consensus regarding cervicitis case definition and standardized, reproducible assay to detect associated sexually transmitted pathogens used in studies[3,19]. The cervicitis patients and asymptomatic individuals enrolled in this study were strictly selected via medical history screening, light microbiology observation, and laboratory tests to exclude the other Sexually transmitted pathogenic, including the fungi, T.trichomonas, HPV, C.trachomatis, and N. gonorrhea.

Our study suggested that the prevalence of U.parvum and U.urealyticum were $51.9 \% \mathrm{Vs}$ $46.9 \%, 8.2 \% \mathrm{Vs} 8.1 \%$ in the two groups, respectively. The difference in the prevalence of those two pathogens between the two groups was not statistically significant. But obviously, the prevalence of U.urealyticum was significantly lower than the U.parvum. Currently, this difference was not completely understood.

By qPCR assay, the mean of Ct of U. urealyticum in two groups is very close, suggesting that $U$. urealyticum may not have a causal role in cervicitis. Due to the almost Ct of qPCR were large than 30, the results of qPCR perhaps not very accurate (Figure no.2). Hence, we taken a 
newest promising PCR technology, droplet digital PCR (ddPCR), that enables the absolute quantitation of nucleic acids and provided higher precision, accuracy and repeatability[15].

Our data suggested that the correlation of U.parvum is higher $\left(\mathrm{R}^{2}=0.80\right.$, Figure no.3a) but of U.urealyticum is relatively poor $\left(\mathrm{R}^{2}=0.50\right.$, Figure no.3e) between two methods. But conclusions are on the whole the same of two methods. As expected, there were significance differences of the copy number of U.parvum in two groups $(P<0.0001)$ and the absolutely copy number in non-specific cervicitis is higher than 10 times compared with the control group (Table no. 4). By contrast, the difference in the copy number of U.urealyticum between two groups was not statistically significant $(P>0.05$, Table no. 4$)$.

Recently, several studies have shifted to focus on the bacteria load. A study suggested that the amount of U.parvum copy number was significant correlation with histologic chorioamnionitis [20]. Similarly, a study was made by Contini $\mathrm{C}$ et al. [21] using qPCR to quantify the bacteria load of U.parvum were $1.3 \times 10^{-1}$ copy/cell in spontaneous abortion (SA, $\mathrm{n}=14)$ and $2.8 \times 10^{-3} \mathrm{copy} / \mathrm{cell}$ in the female who underwent voluntary interruption of pregnancy (VI, $\mathrm{n}=15)$, contrarily, the bacteria load of U.urealyticum were $3.3 \times 10^{-3}$ and $1.6 \times$ $10^{-3}$ copy/cell in SA and VI, respectively.

In the current study, we quantified, for the first time, the precise bacteria load of U.parvum and U.urealyticum through ddPCR technology. It is generally considered that Ureaplasma spp. load $\geq 10^{4} \mathrm{CCU} / \mathrm{ml}$ is the signal of active infection and may require treatment with antibiotics. 
219 The establishment of this reference value is based on the liquid culture. However, traditional 220 liquid culture is only a qualitative method with relatively poor sensitivity, exists of false221 positives and false-negative, and indistinguishable Ureaplasma spp. serovars[22]. At present, 222 real-time PCR has become a common technique in molecular diagnosis and overcomes the above-mentioned shortcomings of liquid culture, and can perform relative quantified or absolute quantification through the standard curve. However, the construction of the standard curve is complicated and time-consuming. Moreover, the quantitative accuracy of qPCR is easily affected by amplification efficiency and PCR inhibitors. 
Our study has several limitations. On the one hand, the standard curves of qPCR had a

wider linear range of 6 log units (Figure no. 1), but ddPCR has smaller dynamic range, lower

throughput, and higher cost due ro specialized instrumentation and consumables (supplement),

which to a large extent limited the application in clinical. On the other hand, the prevalence of

U.urealyticum is relatively lower, the number of population recruited in the study on a whole

was relative smaller. Moreover, this was a single-center cross-sectional study. Multicenter

Prospective studies with a large population in future will provide more definitive evidence.

This study is the first to report on the absolute quantitative bacterial load of Urealyticum spp. in non-specific cervical swabs. The ddPCR assay can quantify the burden of asymptomatic and symptomatic individuals, and provide clinicians with important information on diagnosis and treatment effects. In conclusion, our research on non-specific cervicitis and asymptomatic individuals indicates that the U.parvum rather than U.urealyticum may play a potential role in the development and progression of cervicitis among female. But the pathogenicity of U.parvum might relatively low, only at high dose may induce the inflammation. More research is needed to elucidate the difference in the role of Ureaplasma serotypes and pathogenicity of the relevant clinical diseases of Ureaplasma spp. infection.

\section{Abbreviations}

ddPCR: digital droplet PCR 
264 NSC: non-specific cervicitis

265 PPROM: preterm premature rupture of membranes

266 HPV: Human papillomavirus

267 CT: threshold cycle

268 GAPDH: glyceraldehyde-3-phosphate dehydrogenase

\section{Declarations}

271 Ethics approval and consent to participate

272 The study was approved by the Ethical committee of the Minhang University, Fudan University.

273 The study abides by the ethical norms and principles for research as established by the 274 Declaration of Helsinki. Informed consent was obtained from all subjects. All patients gave 275 permission for the collection of their cervical swabs and for their medical records to be accessed 276 and recorded.

\section{Consent for publication}

278 No.

279 Availability of data and materials

280 The data generated during the current study are available from the corresponding author on 281 reasonable request.

\section{Competing interests}

283 The authors have declared that no conflict of interest exists. Both authors have submitted the 284 ICMJE Form for Disclosure of Potential Conflicts of Interest. 
286 No funding.

\section{Authors' contributions}

288 Yanfang Huang designed the experiments, collected clinical specimens, performed the experiments and analyzed the data, drafted the manuscript.

Xiaoqin Xu, Panpan Lv collected clinical specimens and performed the experiments.

Zhen Zhao designed the experiments, analyzed the data, obtained funding and supervised the study, drafted the manuscript.

All authors participated in revising of the manuscript for important intellectual content. All authors read and approved the final manuscript.

\section{Acknowledgements:}

We are sincerely obliged to Biomed-Union Co. Ltd. (Shanghai, China) and Dr. Wang xinxin for his excellent technical assistance about ddPCR technology.

\section{References:}

[1] Beeton ML, Payne MS, Jones L (2019) The Role of Ureaplasma spp. in the Development of Nongonococcal Urethritis and Infertility among Men. CLIN MICROBIOL REV 32 (4)

[2] Xiao B, Wu C, Song W, Niu X, Qin N, Liu Z, Xu Q (2019) Association Analysis on Recurrence of Bacterial Vaginosis Revealed Microbes and Clinical Variables Important for Treatment Outcome. FRONT CELL INFECT MI 9

[3] Lusk MJ, Garden FL, Rawlinson WD, Naing ZW, Cumming RG, Konecny P (2016) Cervicitis aetiology and case definition: a study in Australian women attending sexually transmitted infection clinics. SEX TRANSM INFECT 92 (3):175-181

[4] Rittenschober-Böhm J, Waldhoer T, Schulz SM, Pimpel B, Goeral K, Kasper DC, Witt A, Berger A (2019) Vaginal Ureaplasma parvum serovars and spontaneous preterm birth. AM J OBSTET GYNECOL 220 (6):591594

[5] Sweeney EL, Dando SJ, Kallapur SG, Knox CL (2017) The Human Ureaplasma Species as Causative Agents of Chorioamnionitis. CLIN MICROBIOL REV 30 (1):349-379

[6] Feng L, Allen TK, Marinello WP, Murtha AP (2018) Infection-induced thrombin production: a potential novel mechanism for preterm premature rupture of membranes (PPROM). AM J OBSTET GYNECOL 219 
[7] Jordan SJ, Toh E, Williams JA, Fortenberry L, LaPradd ML, Katz BP, Batteiger BE, Nelson DE, Batteiger TA (2020) Aetiology and prevalence of mixed-infections and mono-infections in non-gonococcal urethritis in men: a case-control study. SEX TRANSM INFECT 96 (4):306-311

[8] Lusk MJ, Konecny P, Naing ZW, Garden FL, Cumming RG, Rawlinson WD (2011) Mycoplasma genitalium is associated with cervicitis and HIV infection in an urban Australian STI clinic population. SEX TRANSM INFECT 87 (2):107-109

[9] Horner P, Donders G, Cusini M, Gomberg M, Jensen JS, Unemo M (2018) Should we be testing for urogenital Mycoplasma hominis, Ureaplasma parvum and Ureaplasma urealyticum in men and women?-a position statement from the European STI Guidelines Editorial Board. J EUR ACAD DERMATOL 32 (11):18451851

[10] Liu L, Cao G, Zhao Z, Zhao F, Huang Y (2014) High bacterial loads of Ureaplasma may be associated with non-specific cervicitis. Scandinavian Journal of Infectious Diseases 46 (9):637-641

[11] Frølund M, Lidbrink P, Wikström A, Cowan S, Ahrens P, Jensen J (2016) Urethritis-associated Pathogens in Urine from Men with Non-gonococcal Urethritis: A Case-control Study. Acta Dermato Venereologica 96 (5):689-694

[12] Song N, Tan Y, Zhang L, Luo W, Guan Q, Yan M, Zuo R, Liu W, Luo F, Zhang X (2018) Detection of circulating Mycobacterium tuberculosis-specific DNA by droplet digital PCR for vaccine evaluation in challenged monkeys and TB diagnosis. EMERG MICROBES INFEC 7 (1):1-9

[13] Poh TY, Ali NATB, Chan LLY, Tiew PY, Chotirmall SH (2020) Evaluation of Droplet Digital Polymerase Chain Reaction (ddPCR) for the Absolute Quantification of Aspergillus species in the Human Airway. INT J MOL SCI 21 (9):3043

[14] Lillsunde Larsson G, Helenius G (2017) Digital droplet PCR (ddPCR) for the detection and quantification of HPV 16, 18, 33 and 45 - a short report. CELL ONCOL 40 (5):521-527

[15] Hindson CM, Chevillet JR, Briggs HA, Gallichotte EN, Ruf IK, Hindson BJ, Vessella RL, Tewari M (2013) Absolute quantification by droplet digital PCR versus analog real-time PCR. NAT METHODS 10 (10):10031005

[16] Kuypers J, Jerome KR (2017) Applications of Digital PCR for Clinical Microbiology. J CLIN MICROBIOL 55 (6):1621-1628

[17] (2015) Sexually Transmitted Diseases Treatment Guidelines, 2015. ANN EMERG MED 66 (5):526-528

[18] Kumar S, Stecher G, Li M, Knyaz C, Tamura K (2018) MEGA X: Molecular Evolutionary Genetics Analysis across Computing Platforms. MOL BIOL EVOL 35 (6):1547-1549 [19] Taylor-Robinson D, Jensen JS (2011) Mycoplasma genitalium: from Chrysalis to Multicolored Butterfly. CLIN MICROBIOL REV 24 (3):498-514

349 [20] Kasper DC, Mechtler TP, Reischer GH, Witt A, Langgartner M, Pollak A, Herkner KR, Berger A (2010) The bacterial load of Ureaplasma parvum in amniotic fluid is correlated with an increased intrauterine inflammatory response. DIAGN MICR INFEC DIS 67 (2):117-121 [21] Contini C, Rotondo JC, Magagnoli F, Maritati M, Seraceni S, Graziano A, Poggi A, Capucci R, Vesce F, Tognon M, Martini F (2019) Investigation on silent bacterial infections in specimens from pregnant women affected by spontaneous miscarriage. J CELL PHYSIOL 234 (1):100-107

355 [22] Zhao F, Feng X, Lv P, Xu X, Zhao Z (2020) Real-time PCR assay may be used to verify suspicious test results of Ureaplasmas spp. from the liquid culture method. J MICROBIOL METH 169:105831

357 [23] Saha SK, Schrag SJ, El Arifeen S, Mullany LC, Shahidul Islam M, Shang N, Qazi SA, Zaidi AKM, Bhutta 358 ZA, Bose A, Panigrahi P, Soofi SB, Connor NE, Mitra DK, Isaac R, Winchell JM, Arvay ML, Islam M, Shafiq 
360 Hasanuzzaman M, Ahmed S, Belal Hossain M, Ariff S, Ahmed I, Ibne Moin SM, Mahmud A, Waller JL, 361 Rafiqullah I, Quaiyum MA, Begum N, Balaji V, Halen J, Nawshad Uddin Ahmed ASM, Weber MW, Hamer DH,

362 Hibberd PL, Sadeq-ur Rahman Q, Mogan VR, Hossain T, McGee L, Anandan S, Liu A, Panigrahi K, Abraham

363 AM, Baqui AH (2018) Causes and incidence of community-acquired serious infections among young children in 364 south Asia (ANISA): an observational cohort study. The Lancet 392 (10142):145-159

365 [24] Bharat A, Cunningham SA, Scott Budinger GR, Kreisel D, DeWet CJ, Gelman AE, Waites K, Crabb D, 366 Xiao L, Bhorade S, Ambalavanan N, Dilling DF, Lowery EM, Astor T, Hachem R, Krupnick AS, DeCamp MM, 367 Ison MG, Patel R (2015) Disseminated Ureaplasma infection as a cause of fatal hyperammonemia in humans. 368 SCI TRANSL MED 7 (284):283r-284r

369 [25] Glaser K, Silwedel C, Fehrholz M, Waaga-Gasser AM, Henrich B, Claus H, Speer CP (2017) Ureaplasma 370 Species Differentially Modulate Pro- and Anti-Inflammatory Cytokine Responses in Newborn and Adult Human 371 Monocytes Pushing the State Toward Pro-Inflammation. FRONT CELL INFECT MI 7

372 [26] Pavlidis I, Spiller OB, Sammut Demarco G, MacPherson H, Howie SEM, Norman JE, Stock SJ (2020) 373 Cervical epithelial damage promotes Ureaplasma parvum ascending infection, intrauterine inflammation and 374 preterm birth induction in mice. NAT COMMUN 11 (1)

375 [27] Noh EJ, Kim DJ, Lee JY, Park JH, Kim J, Han JW, Kim BC, Kim CJ, Lee SK (2019) Ureaplasma 376 Urealyticum Infection Contributes to the Development of Pelvic Endometriosis Through Toll-Like Receptor 2. 377 FRONT IMMUNOL 10 


\section{Figures}

a

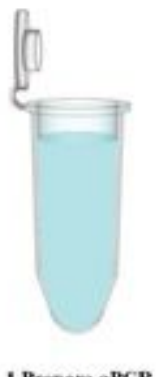

reaction mix

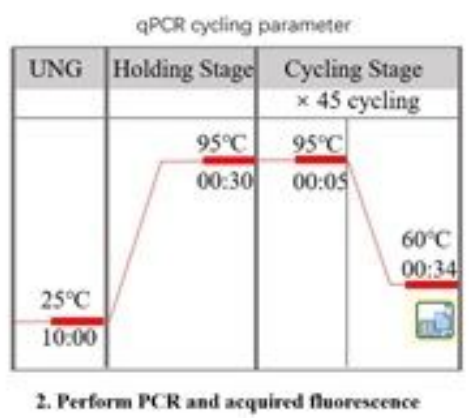

c

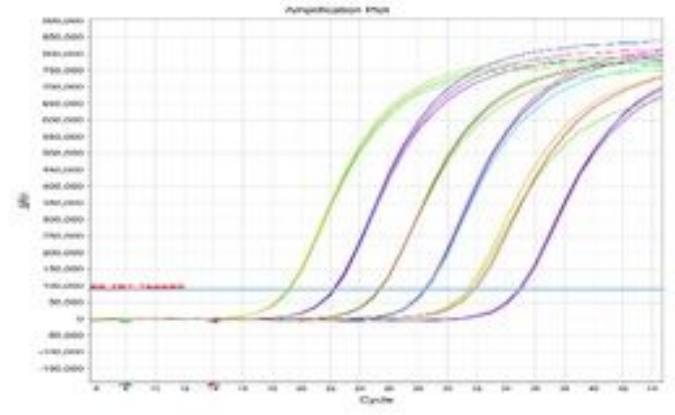

e

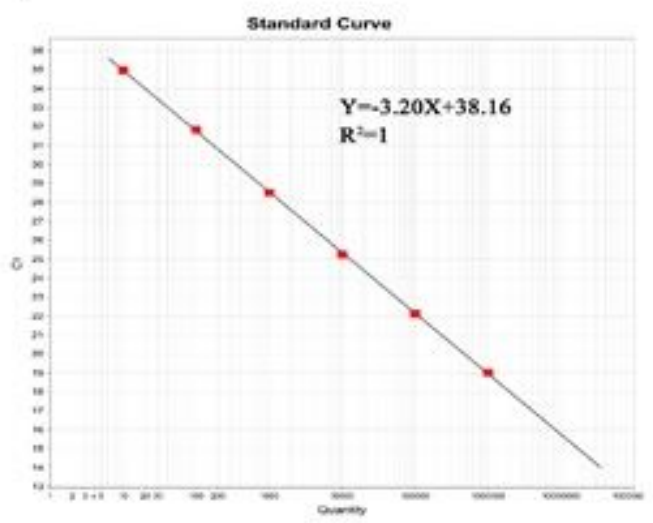

b

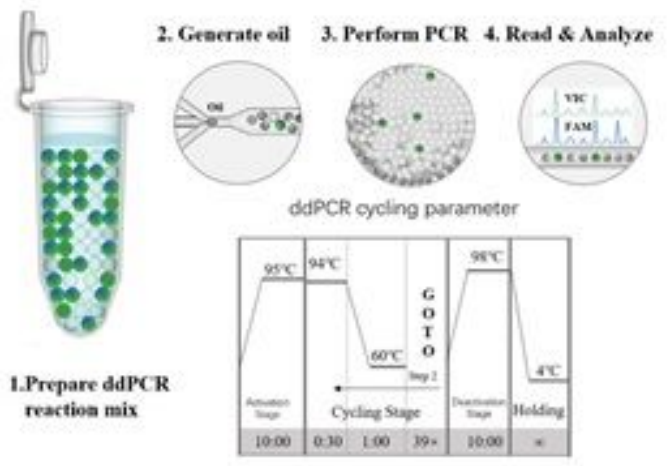

d

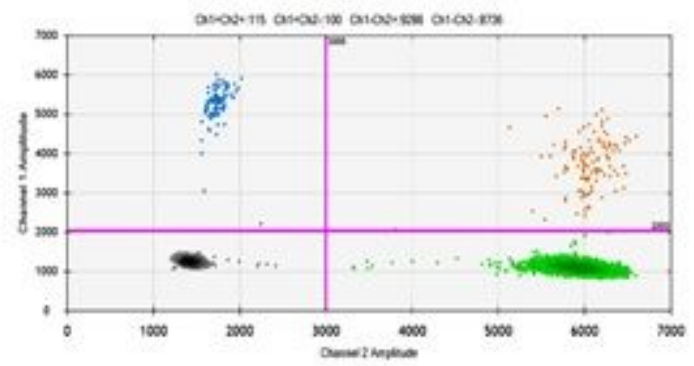

f

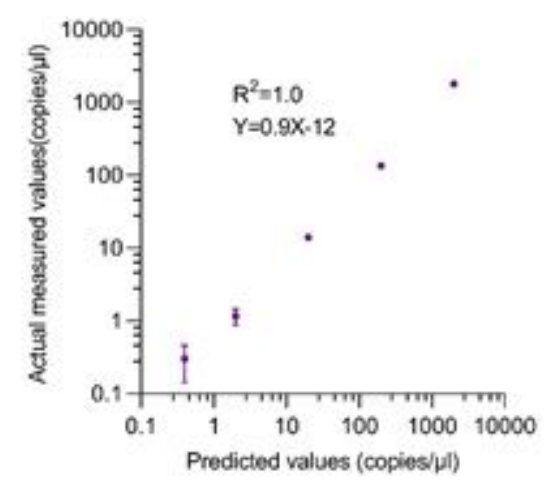

\section{Figure 1}

Schematic diagram illustrates the protocols and key difference between qPCR and droplet digital PCR (ddPCR). (a) The protocol of qPCR. (b) The protocol of ddPCR including the partitioned into 20,000 discrete droplets of a single PCR sample, generated droplet, performed PCR amplification, read droplet and analyzed ddPCR data. (c) Using ten-fold standard dilutions of U.urealyticum to illustrate qPCR linearity. (d) 2-D plot of droplet fluorescence. Set thresholds manually to obtain an accurate quantification of the target. (e) The standard curve of ten-fold standard dilutions of U.urealyticum in qPCR. (f) The standard curve of ten-fold standard dilutions of U.urealyticum in ddPCR. 

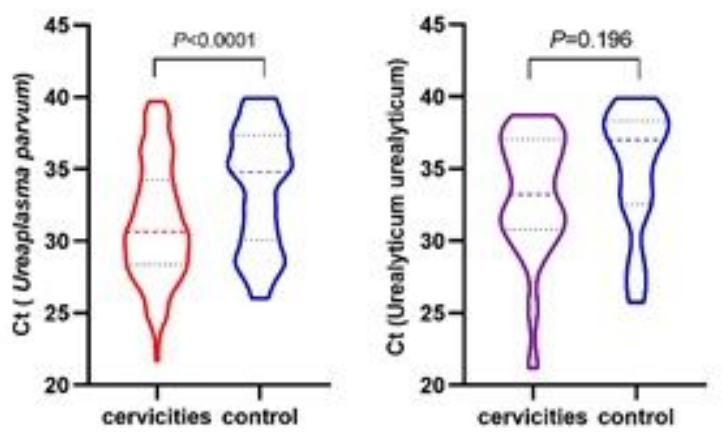

\section{Figure 2}

Violin map for Ureaplasma biovars in cervical swabs form non-specific cervicitis (NSC) patients and controls in qPCR. (a) qPCR results for Ureaplasma parvum; The mean Ct value of U.parvum in NSC group is $31.33 \pm 4.07(n=152)$, the mean Ct value of U.parvum in control group is $33.68 \pm 4.10(n=99)$. (b) qPCR results for Ureaplasma urealyticum. The mean Ct value of U.urealyticum in NSC group is $33.16 \pm 4.31$ $(n=24)$, the mean Ct value of U.urealyticum in control group is $34.97 \pm 4.40(n=17)$. Data are representative of three independent experiments with 3 replicates for each concentration (means $\pm S D$ ).
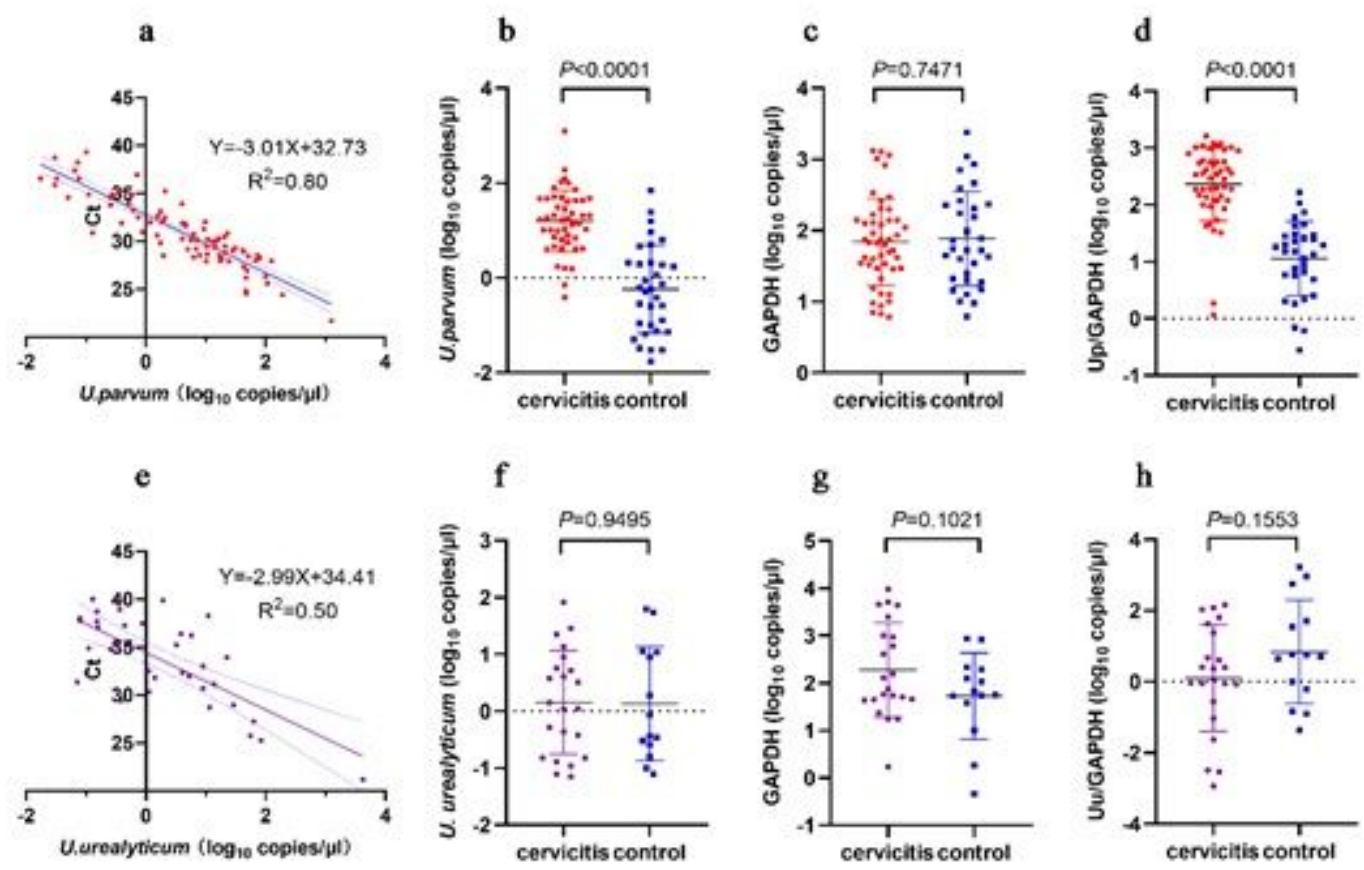

\section{Figure 3}

Ureaplasma biovars in cervical swabs form non-specific cervicitis (NSC) patients and controls in ddPCR. (a) The correlation of U.parvum between the qPCR and ddPCR $(n=81)$. (b) the absolute copy number of U.parvum in NSC $(n=48)$ and control group $(n=33)$ by ddPCR. (c) The absolute copy number of GAPDH in NSC $(n=48)$ and control group by ddPCR $(n=33)$. (d) The standard copy number of U.parvum in NSC $(n=48)$ and control group $(n=33)$ by ddPCR. (e) The correlation of U.urealyticum between the qPCR and 
ddPCR ( $n=37)$. ( $f)$ the absolute copy number of U.urealyticum in NSC $(n=22)$ and control group $(n=14)$ by ddPCR. ( $g)$ The standard copy number of U.urealyticum in NSC $(n=22)$ and control group $(n=14)$ by ddPCR. NSC: Non-specific cervicitis.

\section{Supplementary Files}

This is a list of supplementary files associated with this preprint. Click to download.

- Table1.docx

- Table2.docx

- Table2.docx

- Table3.docx

- Table4.docx

- appendix1.docx

- supplementFigure1.pdf

- supplementFigure2.pdf

- SupplementFigure3.pdf 